\title{
EFL Teachers' Attitudes towards the Effectiveness of Metacognitive Strategies Used by High School Students
}

\author{
Hanieh Garmabi \\ Department of English, Khorasan e Razavi Science and Research Branch, Islamic Azad \\ University, Neyshabur, Iran. \\ Department of English, Neyshabur Branch, Islamic Azad University, Neyshabur, Iran. \\ hanie_garmabi@yahoo.com \\ Gholamreza Zareian (Corresponding Author) \\ Department of English, Khorasan e Razavi Science and Research Branch, Islamic Azad \\ University, Neyshabur, Iran. \\ Department of English, Neyshabur Branch, Islamic Azad University, Neyshabur, Iran. \\ Zareian22@gmail.com
}

Doi:10.5296/ ijld.v6i1.9124 URL: http://dx.doi.org/10.5296/ ijld.v6i1.9124

\begin{abstract}
In any educational program, the most influential factor affecting the students' level of improvement is the teacher (Rama, 2011). Indeed, the teacher is assigned such an importance that his/her attitude is important for improving educational process and more influential than a teacher's knowledge (Xu, 2012). Hence, this study intends to examine the teachers' attitude towards the effectiveness of metacognitive strategies used by high school students. To achieve the study goals, 100 teachers who taught English at different high schools of three Cities of Iran were asked to complete 34 item thesis questionnaire which investigated the teachers' attitude toward the effectiveness of metacognitive strategy use while reading a text. The results of statistical analysis indicated that while male and female teachers have the same attitude about reading and post-reading metacognitive strategies, they have significantly different attitudes about pre-reading metacognitive strategies. The results offer implications and suggestions for the pedagogical considerations within the school and even at university contexts.
\end{abstract}

Keywords: Metacognitive strategy, attitude

\section{Introduction}

In the teaching profession teachers are among the principal components of any pedagogical program (Pettersson, Tina, Postholm, Felm, \& Gudmundsdottir, 2004). It is a known fact that teachers can affect the classroom environment to a large extent. Every individual teacher is an 
important element of what happens in the classroom (de Guerrero \&Villamil, 2002). In fact, the teacher's qualification and effectiveness are the most influential contributors to student success (Wenglinsky, 2000). Suwandee (1995) pointed out that, in the complex process of teaching and learning, the teacher's degree of commitment to the teaching task highly impacts students' achievement. Brown (2001, p. 445) stated that teachers are "agents for change in a world in desperate need of change: change from competition to cooperation, from powerlessness to empowerment, from conflict to resolution, from prejudice to understanding".

Teachers' attitude can be directed toward metacognitive strategies, such as planning, predicting, checking, reality testing, and monitoring which have been proven useful for facilitating learning in classrooms. Students who have a broad repertoire of strategies to use and know when to use them are more effective learners. They are better equipped to plan, monitor, and regulate their cognitive processes in all areas of their lives. Teaching metacognitive skills helps students become life-long students. Without explicit training, students may not realize the importance of metacognitive strategies. In addition to incorporating explicit instruction, instructional designers should realize that good strategy users need time to develop a broad repertoire of strategies and to know why, when, and where to use strategies. Developing and using metacognitive strategies effectively takes time. To help develop the students' use and transfer of metacognitive strategies, the designer should build the modeling of metacognitive strategies into instruction, along with time for the students to practice the strategies. In addition to practicing the strategies, the students should be given time to reflect on the strategy and make explicit the implicit processes they are using. Introducing strategies to students, allowing them to practice the strategies, and helping them recognize their implicit processes should help them not only understand how to use the strategies, but also when and why to use the strategies. Lastly, for metacognitive strategy instruction to be most effective, instructional designers should introduce a variety of strategies to help the students. Because all students have different learning styles and bring a variety of prior learning experiences into the learning environment, instructional designers must account for these differences in order to accommodate all students. Teaching a variety of metacognitive strategies will introduce students to a broad repertoire of strategies, so they will know what strategies work best for them in a variety of situations (Weaver, 2012).

\subsection{Metacognitive Strategies}

Scientific and technological improvements push the countries toward being better and more complete ones to change and develop educational systems and training programs (Akkaya, 2012). As learners are at the central part of an educational context, enhancing their awareness of learning strategies and guiding them to use these strategies are the main objective of teachers and researchers. Metacognitive strategies like planning, self monitoring, and self evaluation are one type of the learning strategies (Takallou, 2011).

Both students and teachers have specific roles in becoming aware and using strategies. Specifically, teachers can provide explicit explanation, demonstrate strategies, help learners 
know when, where, why, and how they should use these strategies, act as a model for them, and give them appropriate feed backs for correcting them. Metacognitive knowledge about reading and reading comprehension changes with the students' age and ability. Since as students get older, they become aware of their own thinking about themselves, tasks, and strategies which are useful for learning, reading, or comprehending; besides, good comprehenders or competent learners, are always more aware of metacognitive knowledge than poor and less competent ones. Metacognitive knowledge is domain-specific which means that students may have metacognitive knowledge in a specific area, but not in another, or sometimes students may know several aspects of metacognitive knowledge, but they may not be able to report or express them. language ability might be a key factor contributory to these difficulties, in addition, factors like motivation and working memory may cause learners fail to use metacognitive strategies to regulate their learning there is an agreement on this view that good readers use multimedia strategies flexibly while, poor reader have less strategy use, less control on using them, and more difficulty in adjusting strategies to the texts rather than good ones. Reading comprehension can be improved by teaching students to use metacognitive and comprehension -related strategies. Although a large number of strategies have been suggested by educators and teachers, the most commonly taught strategies having strong empirical support are: making predictions, questioning, summarizing, and clarifying (Kraayenoord, 2010).

Four approaches for metacognitive training were introduced in the research reviewed by Ellis, Denton, and Bond (2014). The first and the most widely used approach was modeling showing students the procedures to follow a specific strategy. The teacher modeling a strategy should explain the usefulness of that strategy to students first, and then verbalize what they are doing, why they are doing and ways for overcoming the problems. The second common approach was diagramming, similar to modeling, but a kind of visual learning. Practice was the third one, which is the most effective metacogniive strategy instruction. At last, mnemonics, answer checking, check list and goal attainment were the next additional approaches to metacognitive training.

The present study done by Rahimi and Abedi (2014) investigated EFL learners' metacognitive awareness of listening strategies with their listening self-efficacy.To reach their aim, the researchers chose 371 learners studying in grade three and four high school in different majors in order to fill English listening self-efficacy questionnaire and metacognitive awareness listening questionnaire. Findings of the study revealed that there is a positive and significant relationship between metacognitive awareness of listening strategies and listening self-efficacy. Moreover, the findings showed that listening self-efficacy related positively to planning-evaluation and problem solving strategies, but it was inversely related to mental translation strategies.It was also found that EFL learners have an average level of metacognitive awareness of listening strategies which is attributed to EFL learners' limited listening experience and type of instruction they received before.

In line with Rahimi and Abedi's research (2014), this study done by Rahimirad (2014) explored the relationship between metacognitive strategy instruction and listening performance. In order to answer the research question, researcher selected 50 students whose 
English proficiency was around intermediate level, and then divided them into experimental (n: 25) and control (n: 25) groups. All the participants took TOEFL listening post-test and pre-test, although only experimental group received the listening input and exercises through explicit metacognitive strategy instruction. Finally, the comparison between experimental and control groups' post-test and pre-test indicated that treatment group who were taught metacognitive strategy out performed in listening test control group who were taught by traditional methods. Furthermore, findings of study showed that teaching metacognitive strategies can facilitate and accelerate listening performance. It can also make learners more independent, self-regulated, self-confident, and responsible of their own learning via dealing with five factors of metacognitive knowledge (planning and evaluation, problem solving, directed attention, mental translation and person knowledge).

Similarly, Selamat and Sidhu (2013) investigated the effects of metacognitive strategy training on listening comprehension ability. To this end, 34 students from Malaysian university were selected and asked to take a pre-test of listening comprehension before they start their strategy training courses. During 10 weeks, the students underwent a program of learning and utilizing, metacognitive listening strategy. At the end of treatment, the students took a post-test. Finally, the results revealed that students can benefit from instructions in metacognitive listening strategies because it was indicated that there were improvements in the students' listening comprehension abilities which can be associated with the application of listening strategies. It was also found that there is a lack of awareness of metacognitive listening strategies among students which was explored by Metacognitive Awareness Listening Questionnaire and semi-structured interview.

To gain more insight about metacognitive strategy, Kisac and Budak (2014) decided to explore the relationship between self-confidence level of students and their use of metacognitive skills or strategies. Study group of this research, 400 university students, were randomly chosen. After collecting data through Managing Metacognition Inventory, It became apparent that students who have higher self-confidence use metacognition skills more. Generally, these students more use the strategies of note taking, summarizing, reflecting, reciting, and reviewing what they have learned. Of course, this finding can be interpreted in two ways. Firstly, students having higher self-confidence use more metacognitive skills; secondly, using more metacognitive strategies makes students more self-confident.

\subsection{Metacognitive Strategies and Reading Comprehension}

Having an idea that knowing and using reading strategies accounts for reading improvements, these researchers highlighted the importance of metacognitive strategies for comprehending a difficult text. Pammu, Amir, and Maasum (2014) conducted a research on metacognitive reading strategies with 40 less proficient EFL learners. Participants' metacognitive awareness of reading strategies was measured through Metacognitive awareness of Reading Strategy Inventory Questionnaire. The questionnaire included three sub scales of reading strategies; first, Global reading strategies concerning global analysis of text such as previewing text and understanding the purpose of reading ; second, support strategy dealing with using 
dictionary, taking notes, and summarizing important information; third, problem solving strategy concerning finding out a solution when comprehension problems arise and adjusting reading speed. From the analyzing of data gathered in this study it was it was indicated that less proficient learners, larger in number than the proficient learners, have high level of metacognitive awareness for problem solving strategy but medium level for support and global strategies. They were more interested in using top-down strategies and using reference material like dictionary but didn't use compensation strategy or meta-analysis text as efficient learners. So, they needed to more reading strategy instruction to generate their metacognitive awareness for improving their proficiency level.

The current research done by Cox (2005) wanted to explore whether implication of metacognitive strategies improve the learners' reading comprehension. To answer the study question, 10 students who had reading difficulties selected. The teaching group was explicitly taught how to use metacognitive strategies for improving their reading comprehension. Findings of this study showed that one of the ways for improving the learners' reading comprehension is to make them strategic readers by providing for them a greater repertoire of metacognitive strategies. In other words, it's approved in this study that explicit strategic training helps learners to improve their own learning and comprehension.

In the current study which has done by Takallou (2011) the effect of metacognitive strategies (planning and self monitoring) on EFL learners' reading comprehension was examined. To this end, 93 learners were asked to complete a reading comprehension test and strategy inventory for language learning. Participants in excremental group of this study received metacognitive strategy instruction in the reading course, but those participated in control group didn't have such instruction. The results of study showed that students from experimental group outperformed the other group in the reading comprehension test. In other words, the explicit instruction and practice metacognitive strategy is lead to reading improvement. In addition, the results of study revealed that type of a reading text had an important role in the learners' comprehension. As the students performed much better when they were dealt with an authentic text rather than an inauthentic one.

According to Sen (2009) learning and implementing special reading strategies help learners not only use the time more efficiently but also read and comprehend easier and better. Developing strategic reading skills directly related to enhancing brain power. Learners who are aware of their thinking process use metacognitive strategy to develop strategic reading skills. To explore the relationship between metacognitive strategy use and reading comprehension, this researcher carried out a study by 190 students; 95 in experimental and 95 in control group. By using reading comprehension test and metacognitive strategies awareness scale, they collected data which related that reading comprehension achievement scores of students in experimental group who learned use of metacognitive strategies where much higher than the scores of students in control group. In other words, the more use of metacognitive strategies, the more success in reading comprehension. Furthermore, this study suggested that students should be taught strategic reading skills.

The study done by Mehrdad, Ahghar, Ahghar (2012) conducted to investigate the effects of 
teaching cognitive and metacognitive strategies on EFL students' reading comprehension regarding to their proficiency levels. To reach their aims, the researchers, first of all, selected one hundred and eighty B.A students majoring in English and divided them (based on their scores on test of Michigan) into three proficiency groups, Advanced, intermediate, and elementary students. After that, the participants of each group were divided into sub-groups of control and experimental. Those in experimental group were taught cognitive and metacognitive strategies, but those in control group had an instruction on vocabulary and grammar without any strategy training. At the end of treatment, whole the subjects took part in a reading comprehension test. After analyzing the data collected by SPSS statistical package, it was revealed that teaching cognitive and metacognitive strategies had no effects on reading comprehension ability of elementary students; however, it had significant effects on intermediate and advanced students' reading comprehension. In short, it can be inferred from this study that the degree of linguistic knowledge plays a vital role in students' capability to take benefits from cognitive and metacognitive instruction.

However, as far as we know, little if any empirical evidence exists to enable us to determine what is EFL teacher attitude toward student learning strategies. Hence, there is a dearth of evidence showing teachers' attitude towards these strategies of thinking in an educational setting (Ellis, Denton, \& Bond, 2014). In line with this, our study will investigate the relationship between attitude and metacognitive strategies to see how teachers' attitude and students' learning strategies are related to each other.

Q1: Is there any significant difference between male and female teachers' attitude about pre reading strategies?

Q2: Is there any significant difference between male and female teachers' attitude about reading strategies?

Q3: Is there any significant difference between male and female teachers' attitude about post reading strategies?

\section{Methodology}

\subsection{Participants}

The participants of this study were one hundred teachers who taught English at different high schools of three Cities of Iran (Neyshabur, Mashhad, and Torbate Heidarie). Of those, 12 participations did not answer the question of gender and academic degree, leaving 88 participants. A total of 22 male teachers have bachelor's degree and 27 have master's degree while 33 female teachers have bachelor's degree and 6 have master's degree. For both groups of the participants, no distinction was made between males and females. All teachers, who had between 4 and 15 years of teaching experience, voluntarily filled out the thesis questionnaire. 


\subsection{Instrumentation}

\subsubsection{Questionnaire}

The instrument used in this study was a questionnaire developed from Mokhtari and Reichard's (2002) questionnaire called Metacognitive Awareness of Reading Strategies Inventory (MARSI). After the administration of this questionnaire in the pilot phase, according to the insights obtained from university instructors, some questions were modified and some questions were added to it.

The final questionnaire consisted of two parts: the first part required the demographic information of the participants in terms of gender, degree, age, and teaching experience. The second part included 34 items investigated the teachers' attitude toward the effectiveness of metacognitive strategy use while reading a text. The items were classified to three main categories: some related to pre-reading metacognitive strategies, some of them related to reading metacognitive strategies, and the rest related to post-reading metacognitive strategies. Each item was followed by a 5-point Likert Scale, ranging from "strongly agree" to "strongly disagree". Then the teachers as the participants of the study were asked to tick based on their own ideas.

The results of reliability analysis exhibited that the reliability of each part of the questionnaire is very high (Cronbach' alpha for post reading is .83, for reading is .69 , and for pre reading is .59).

\subsection{Data Collection and Data Analysis Procedure}

At the first step, the researcher selected MARSI as a questionnaire, and asked some experienced university instructors to fill it and give their own ideas about it in order to help the researcher to amend the questionnaire and modify its items according to the research title and questions. In the next stage, as mentioned before, some changes were applied to this questionnaire based on the knowledge obtained from the university instructors in the previous stage, and then it was given to high school teachers who taught English. The thesis questionnaire required the participants to determine their own views about the effectiveness of metacognitive strategies while reading a text based on their own educational experiences.

This study employed a quantitative approach to analysis of attitude. For the purpose of analyzing the data, the items in the thesis questionnaire were classified to three groups of Pre-reading, Reading, and Post-reading strategies. Then, the mean of each group based on a special group of participants was computed. SPSS (version 19) was used in order to run the Mann-Whitney U test and Leven's test to find out whether the differences among the three kinds of metacognitive strategies chosen by different participants (male vs. female teachers) were significant. Besides, Cronbach's Alpha was used to measure the internal consistency of the three dimensions of study (Pre reading and Reading and Post reading strategies). 


\section{Macrothink}

\section{Results}

\section{1. Introduction}

In this chapter, research questions followed by the descriptive and inferential results are presented.

3.2. Research Question 1: Is there any significant difference between male and female teachers' attitude about pre reading strategies?

\subsubsection{Descriptive Results}

Table 3.1. Descriptive Statistics of male and female teachers' attitude about Pre reading strategies

\section{Ranks}

\begin{tabular}{|c|l|l|l|l|}
\hline & Gender & $\mathrm{N}$ & Mean Rank & Sum of Ranks \\
\hline Male & 49 & 36.51 & 1789.00 \\
pre reading & Female & 39 & 54.54 & 2127.00 \\
Total & 88 & & \\
\hline
\end{tabular}

The above table shows that out of 88 participants, 49 were male and 39 were female teachers. Comparing the mean ranks of male and female teachers shows that Mean Rank of male teachers' attitude about pre reading strategy is 36.51, and mean rank of female teachers' attitude is 54.54 .

\subsubsection{Inferential Results}

\subsubsection{Testing normality assumption of variables}

According to the hypotheses of this study that compare the means regarding to three dimensions including pre reading and reading and post reading, it is essential to determine the equality of variances, so One-Sample Kolmogorov-Smirnov test was used. 


\section{Macrothink \\ International Journal of Learning \& Development \\ ISSN 2164-4063 2016, Vol. 6, No. 1}

Table 3.2. One-Sample Kolmogorov-Smirnov Test

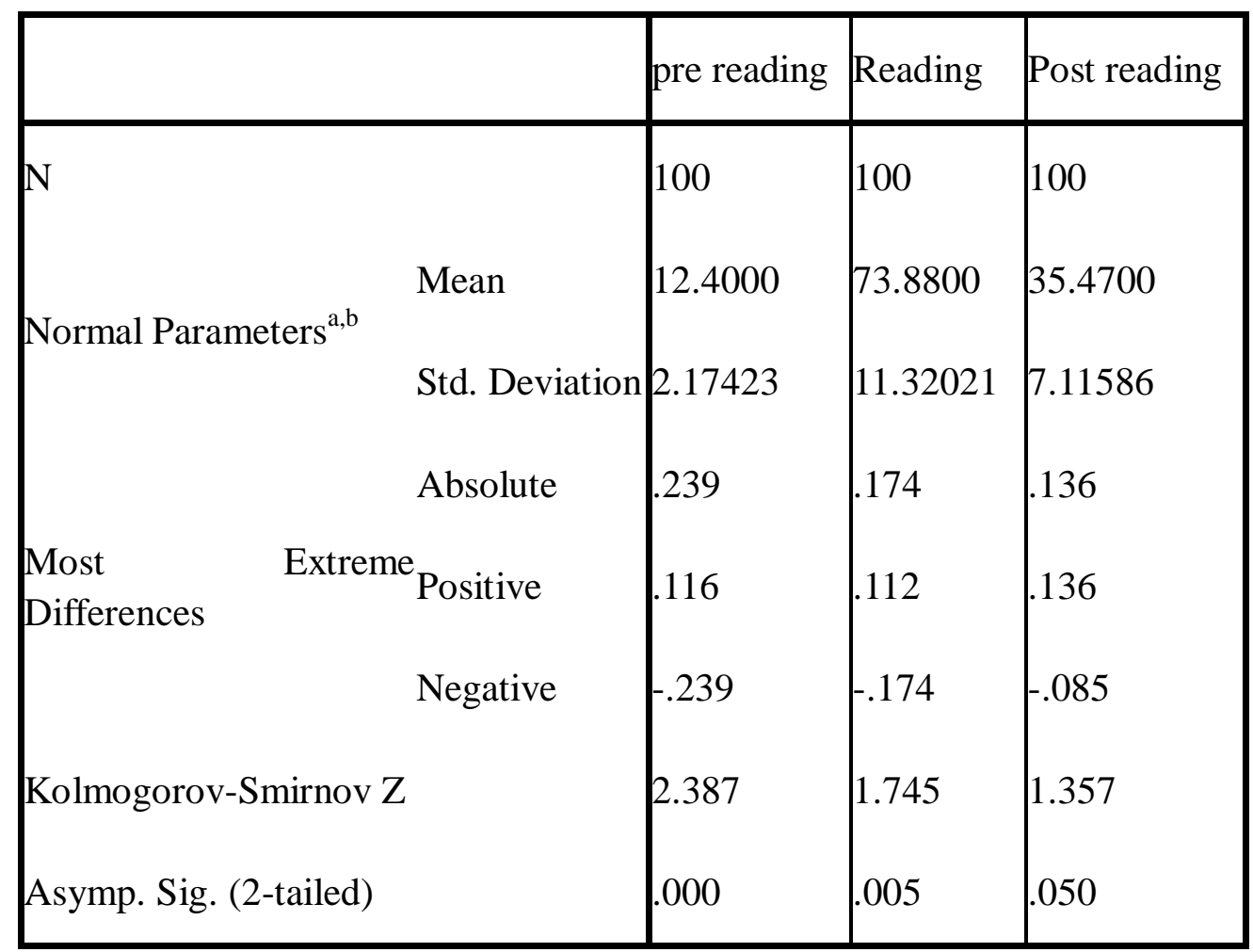

According to the data given in the above table, variables including pre reading and reading have a non-normal distribution, but Post reading is normally distributed. So, for normally distributed variables (pre reading and reading) the Mann-Whitney U test will be used; for normally distributed variable (post reading) two independent T-test will be used.

Table 3.3. Mann-Whitney U test

Test Statistics ${ }^{\text {a }}$

\begin{tabular}{|l|l|}
\hline & pre reading \\
\hline Mann-Whitney U & 564.000 \\
Wilcoxon W & 1789.000 \\
$Z$ & -3.371 \\
Asymp. & Sig. \\
(2-tailed)
\end{tabular}


a. Grouping Variable: gender

From data shown in this table $(\mathrm{Z}=-3.371$ and $\mathrm{Sig}=.001)$, it can be deduced that male and female teachers' attitude about pre reading strategies are not the same, but significantly different.

3.3. Research Question 2: Is there any significant difference between male and female teachers' attitude about reading strategies?

\subsubsection{Descriptive Results}

Table 3.4. Descriptive statistics of male and female teachers' attitude about Reading strategies

\section{Ranks}

\begin{tabular}{|c|l|l|l|l|}
\hline & Gender & $\mathrm{N}$ & Mean Rank & Sum of Ranks \\
\hline Male & 49 & 45.45 & 2227.00 \\
Reading & Female & 39 & 43.31 & 1689.00 \\
& Total & 88 & & \\
\hline
\end{tabular}

According to the above able, out of 88 participants who participated in this study, 49 were male and 39 female teachers. Comparing the mean ranks of male and female teachers shows that mean ranks of male teachers' attitude about reading strategy is 45.45 , and mean rank of female teachers' attitude is 43.31 . 


\subsubsection{Inferential results}

Table 3.5. Mann-Whitney U test

\section{Test Statistics ${ }^{\mathrm{a}}$}

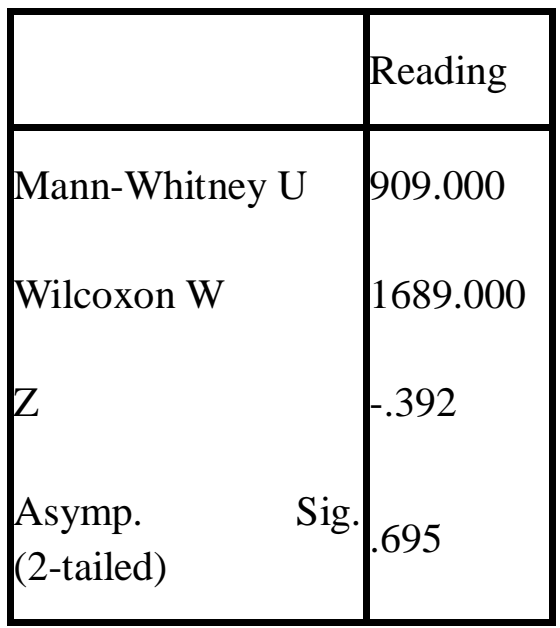

a. Grouping Variable: gender

From data shown in this table $(\mathrm{Z}=-.392$ and $\mathrm{Sig}=.695)$, it can be deduced that male and female teachers' attitude about reading strategies is the same, and any significant difference between them can not be seen.

3.4. Research Question 3: Is there any significant difference between male and female teachers' attitude post reading strategies?

\subsubsection{Descriptive Results}

Table 3.6. Descriptive statistics of male and female teachers' attitude about Post reading strategies

\section{Group Statistics}

\begin{tabular}{|l|l|l|l|l|l|}
\hline & Gender & $\mathrm{N}$ & Mean & Std. Deviation & $\begin{array}{l}\text { Std. Error } \\
\text { Mean }\end{array}$ \\
\hline $\begin{array}{l}\text { Post } \\
\text { reading }\end{array}$ & Male & 49 & 35.5918 & 5.70423 & .81489 \\
& Female & 39 & 34.0000 & 8.47597 & 1.35724 \\
\hline
\end{tabular}




\section{Macrothink}

International Journal of Learning \& Development

ISSN 2164-4063

2016, Vol. 6, No. 1

This table shows that the sample was composed of 49 male and 39 female. As you can see, the average difference between male and female teachers' attitude about Post reading strategy is about 1.5, and difference can be seen in the standard error of the mean and standard deviation, too.

\subsubsection{Inferential Results}

Table 3.7. Comparison between male and female teachers' attitude about Post reading strategies

\section{Independent Samples Test}

\begin{tabular}{|c|c|c|c|c|c|c|c|c|c|}
\hline \multirow[t]{3}{*}{ Post reading } & \multicolumn{2}{|c|}{$\begin{array}{l}\text { Levene's Tes } \\
\text { for Equality } \\
\text { of Variances }\end{array}$} & \multicolumn{7}{|c|}{ t-test for Equality of Means } \\
\hline & \multirow[t]{2}{*}{$F$} & \multirow[t]{2}{*}{ Sig. } & \multirow[t]{2}{*}{$T$} & \multirow[t]{2}{*}{ df } & \multirow[t]{2}{*}{$\begin{array}{l}\text { Sig. } \\
(2-\text { tailed }\end{array}$} & \multirow[t]{2}{*}{$\begin{array}{l}\text { Mean } \\
\text { Differenc } \\
\text { e }\end{array}$} & \multirow[t]{2}{*}{$\begin{array}{l}\text { Std. Error } \\
\text { Differenc } \\
\text { e }\end{array}$} & \multicolumn{2}{|c|}{$\begin{array}{l}95 \% \text { Confidence } \\
\text { Interval of the } \\
\text { Difference }\end{array}$} \\
\hline & & & & & & & & Lower & Upper \\
\hline $\begin{array}{l}\text { Equal variances } \\
\text { assumed }\end{array}$ & 9.758 & .002 & 1.050 & 86 & .297 & 1.59184 & 1.51594 & -1.42176 & 4.60544 \\
\hline $\begin{array}{l}\text { Equal variances not } \\
\text { assumed }\end{array}$ & & & 1.006 & 63.774 & .318 & 1.59184 & 1.58308 & -1.57095 & 4.75462 \\
\hline
\end{tabular}

Results obtained from Leven' s Test showed that there is few difference between male and female teachers' attitude about Post reading strategy which can not be generalized to the whole population $(\mathrm{T}=1.006$, sig $=.318)$. Therefore, it can be stated that male and female teachers in this population have the same attitude about Post reading strategies.

\section{Conclusion and Implication}

As far as, the role of cognitive and metacognitive strategy use in reading comprehension has been a conventional topic of discussion in second language learning (Phakiti, 2006), this study explored the teachers' attitude toward the effectiveness of Metacognitive strategies in three sections: pre-reading, reading, and post-reading. At the first stage of the study, teachers' attitudes about the use of Metacognitive strategies were compared with each other in terms of their gender. From the information obtained from the thesis questionnaire and statistical analysis, it can be concluded that there is no significant difference between male and female teachers' attitude about using reading and post-reading metacognitive strategies; however, 
male and female teachers have significantly different attitudes about pre-reading metacognitive strategies. In other words, the first hypothesis that is There is no significant difference between male and female teachers' attitude about pre reading strategies is rejected, yet the second hypothesis that is There is no significant difference between male and female teachers' attitude about reading strategies and the third hypothesis that is There is no significant difference between male and female teachers' attitude about post- reading strategies are accepted. Such results implicate that as far as males and females differ from each other physically, mentally, and psychologically, they may hold different opinions and attitude towards different concepts. Hence, based on the study's findings, male and female teachers hold different attitude towards some of the metacogntive strategies and same attitude towards others. To put it more specifically, female teachers compared to male teachers showed more tendencies toward the use of Metacognitive strategies in reading skill.

This finding regarding the differences between male and female teachers' attitude toward the use of metacognitive strategies nearly reflects the results gained by Ciascai, liliana, and lavinia (2011) which asserted that although there were differences between the males and females in terms of metacognitive strategy use, the differences occurred solely for specific metacognitive skills. They, also, concluded, based on their study, that differences might be dependent on the ones' will and effort, teachers' expectation, knowing one's own strengths and weaknesses, and frequency of various learning strategy use.

\section{Limitation of Study}

To bring the confines of the research within bounds amenable to study, certain limitations had to be imposed on it. Two of these delimitations are as follows: the main limitation refers to the sample which may be just from some cities of Iran, and then it is a little difficult to generalize the findings. In other words, the size of the studied sample can be increased to produce more valid generalizations based on the results of the study. The second limitation is that the data gathered through one questionnaire; however, more instruments such as survey or interview could be employed.

\section{References}

Akkaya, D. M. S. R. (2009). The levels of metacognitive awareness of primary teacher trainees. Procedia Social and Behavioral Sciences, 1, 1919-1923.

Brown, H. D. (2001). Teaching by principles: An interactive approach to language pedagogy. San Francisco: Longman.

Ciascai, Liliana, \& Lavinia, H. (2011). Gender differences in metacognitive skills. A study of the 8th grade pupils in Romania. Procedia Social and Behavioral Sciences, 29, 396 - 401.

Cox, M. T. (2005). Metacognition in computation: A selected research review. Artificial Intelligence, 169, 104-141.

de Guerrero, M., \& Villamil, S. (2002). Metaphorical conceptualizations of ESL teaching 
and learning. Language Teaching Research, 6, 95-120.

Ellis, A. K., Denton, D. W., \& Bond, J. B. (2014). An analysis of research on metacognitive teaching strategies. Procedia Social and Behavioral Sciences, 116, 4015 - 4024.

Kisac, I., \& Budak, Y. (2014). Metacognitive strategies of the university students with respect to their perceived self-confidence levels about learning. Procedia Social and Behavioral Sciences, $116,3336-3339$.

Kraayenoord. C.E. The Role of Metacognition in Reading Comprehension. 277-302.

Mehrdad, A. G., Ahghar, M. R., \& Ahghar, M. (2012). The effect of teaching cognitive and metacognitive strategies on EFL students' reading comprehension across proficiency levels. Procedia - Social and Behavioral Sciences, 46, 3757 - 3763.

Pammua, A., Amirb, Z., \& Maasum, T. M. (2014). Metacognitive Reading Strategies of Less Proficient Tertiary Learners: A Case Study of EFL Learners at a Public University in Makassar, Indonesia. Procedia - Social and Behavioral Sciences, 118, 357 - 364.

Pettersson, T., Tina, Postholm, M. B., Flem, A., \& Gudmundsdottir, S. (2004). The classroom as a stage and the teacher's roles. Teaching and Teacher Education, 20, 589-605.

Phakiti, A. (2006). Modeling cognitive and metacognitive strategies and their relationships to EFL reading test performance. Melbourne Papers in Language Testing, 1, 53_95.

Rahimi, M., \& Abedi, S. (2014). The relationship between listening self-efficacy and metacognitive awareness of listening strategies. Procedia - Social and Behavioral Sciences, $98,1454-1460$.

Rahimirad, M. (2014). The impact of metacognitive strategy instruction on the listening performance of university students. Procedia - Social and Behavioral Sciences, 98, 1485 1491.

Rama, S. (2011). Professor's performance for effective teaching. Procedia Social and Behavioral Sciences, 12, 117-121.

Selamat, S., \& Sidhu, G. K. (2013). Enhancing listening comprehension: The role of metacognitive strategy instruction (MetSI). Procedia - Social and Behavioral Sciences, 90, $421-430$.

Sen, H. S. (2009). The relationsip between the use of metacognitive strategies and reading comprehension. Procedia Social and Behavioral Sciences, 1, 2301-2305.

Suwandee, A. (1995). Students' perceptions of university instructors' effective teaching characteristics. Studies in Languages and Language Teaching, 5, 6-22.

Takallou, F. (2011). The effect of metacognitive strategy instruction on EFL learners' reading comprehension performance and metacognitive awareness. Asian EFL Journal, 272-300.

Weaver, S. O. (2012). the effects of metacognitive strategies on academic achievement, metacognitive awareness, and satisfaction in an undergraduate online education course. 


\section{Macrothink}

International Journal of Learning \& Development ISSN 2164-4063 2016, Vol. 6, No. 1

Doctoral dissertation, University of South Alabama.

Wenglinsky, H. (2000). How teaching matters: Bringing the classroom back into discussions of teacher quality. Princeton: The Milken Family Foundation and Educational Testing Service.

$\mathrm{Xu}, \mathrm{L}$. (2012). The role of teachers' beliefs in the language teaching-learning process. Theory and Practice in Language Studies, 2(7), 1397-1402. 